
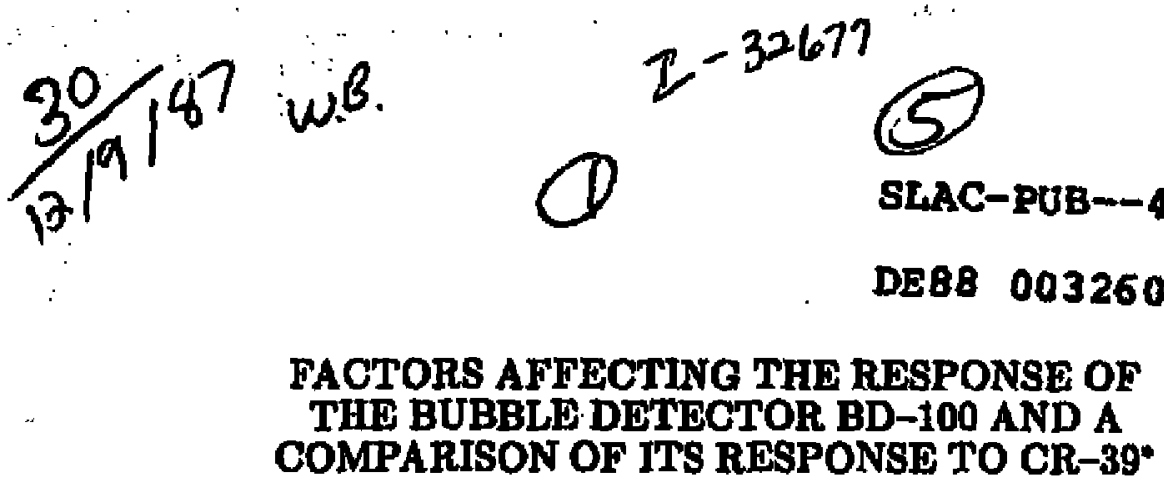

\title{
FACTORS AFFECTING THE RESPONSE OF THE BUBBLE DETECTOR BD-100 AND A COMPARISON OF ITS RESPONSE TO CR-39*
}

\author{
N. E. IPE, D. D. BUAICK \\ Stanford Linear Ateclerator Center \\ Stonjord Univeraity, Stanford, Californja O4905 \\ and \\ R. W. POLLOCK \\ $\cdots \rightarrow$ Siemens Cammasonice, Dee Plaines, iL 60018, U.S.A.
}

\begin{abstract}
The BD-100 is a bubble detector avallable commercially from Chalk River Nuclear Laboratories, Canada for neutron dosimetry. According to the manufacturer, tho BD-100 detecte neutronu over an energy range of $100 \mathrm{keV}$ to $14 \mathrm{MeV}$ and the dose equivalent response is Independent of energy. The sensitivity of the detector is dependent upon ite temparatore at the time of irradiation.

The sensltized detector self-nucleates upon sharp impact and when heated to temperatures of $48^{\circ} \mathrm{C}$ or grester. The $\mathrm{BD}-100$ is insensitive to low energy gamme rays but responds to $6 \mathrm{MeV}$ photoss. The ensitivity (bubbles/ $\mu 5 v$ ) of the BD-10D was found to be energy dependent when exposed to standerd neutron sources with average energles sanging from 0.5 to $4.5 \mathrm{MdV}$. The bubbles formed upon irradiation continued to grow in size with time. The reaponge of electrochemically etched CR-39 to the same neuteon sources is also reported for comparion.
\end{abstract}

Presented at the 6th Symposium on Neutron Dosimetry Neuherberg, Germany, October 12-18; 1987

'Work suppotted by the Department of Energy, contract DE-AC03-76SFo0515. 
detector are reported. The response of the detector to standard neutron sources with average energies ranging from 0.5 to $4.6 \mathrm{MeV}$ is presented. Since CR-39 is also being used for fast neutron detection, its energy response under similar Irradiation conditions to also presented for comparison.

\section{PRINCIPLE OF OPERATION}

Apfel's superheated drop detector ${ }^{3,4}$ and the BD-100 operate on the same principle, namely boiling in a superhested liquid can be initiated by the presence of secondary charged particles formed by radiation interactions with the detector. These charged particles depoait energy along their path, thus initiating the vapor bubble formation. The actual mechanism of vapor bubble nucleation is not fully understood but can be explained using Seits's thermal spike model. According to this model, Intenge lonization and excitalion slong the path of the charged particle produces local heating, thus reaulting in the formation of a minute vapor bubble. If a bubble reaches a size (defned by the critical radiug) that makes it thermodynamically ungtable, it will grow to a visible aize by the evaporation of the superhested liquid until the whole droplet is consumed. The critical radius $R_{e}$ is given by

$$
R_{\mathrm{c}}=\underset{2 \gamma}{\gamma}(\boldsymbol{T}) / \Delta \mathbf{P}
$$

where $\gamma(T)$ is the eurface tension at temperature $T$ and $\Delta P$ is the pressure difference between the vapor pressure of the superheated liquid droplet and the ambient preasure (i.e., pressure exerted on the droplet by the polymer). Thus $\Delta P$ is a measure of the degree of superheat. $A s \Delta P$ increase $R_{e}$ decreases and the energy or heat required for vaporization of the droplet is less. Thus the 
more superheated a liquid is the lese energy it needs to initiate bubble formation. The neutron energy threshold of detection depends upon the critical radius and the stopping power (i.e., the amount of energy deposiled per unit path length) of the secondary charged particle. For a neutron of a given energy interacting with a given detector medium, the neutron energy threshold can be lowered by increasing $\Delta P$.

\section{EXPERIMENTAL METHODS}

Three batches of detectors with sensitivities to PuBe neutrons of $0.198,0.240$ and 0.242 bubbles $/ \mu \mathrm{S} v$ at $20^{\circ} \mathrm{C}$ (within $10 \%$ as quoled by the manufactures) were used in these atudies. The bubble detectors were normally stored in the refrigerator and were taken out of the refrigerator about an hour before use. The delectors were sensitized as described earlier, and usually used within fifteen minutes after sensitization. According to Ing ${ }^{\mathfrak{h}} 100 \%$ of the sensitivity is obtained when the BD-100 is used within eight hours after sensitization. Immediately after irradiation electronic contact cleaner (containing freon) was introduced into the delector tube and the recapped detector was stored at room temperature. The detectors were usually counted about 15 hours or more after irradiation. This elapsed time period allowed the bubbles to grow to a reasonable size which facilitated the counting process described below. The magnified image of the bubble detector was projected on the T.V. gcreen with the aid of a video camera. A light source with varjable intensity and orientation was used to obtain the best possible image on the screen. Each detector was rotated three times and the number of bubbles counted by scoring on a transparency sheet overlaying the T.Y. ecreen. The highest reading for each delector was recorded. 


\section{DISCLAIMER}

This report was prepared as an account of work sponsored by an agency of the United States Government. Neither the United States Goveroment nor any agency thereof, nor any of their employes, makes any warranty, express or inplied, or assumes any legal liability or responsibility for the accuracy, completeness, or usefulness of any information, apparatus, product, or process disclosed, or represents that its use would not infringe privately owned rights. Referenee herein to any specific commercial product, process, or service by trade name, trademark, manufacturer, or otherwise does not neceserarily constitute or imply its endorsenent, recommendation, or favoring by the United States Government or any agency thereof. The views and opinions of anthors expressed berein do not necesesrily state of reflect those of the United States Government or any agency thereof. 
All neutron irradiations were performed outdoors in a low scatter surrounding with the detectors mounted on a water phanlom. Corrections for neutron geattering and anisotropy of the neutron sources (except ${ }^{2 \mathrm{~B} 2} \mathrm{Cf}$ ) were made in calculating the neutron filuences. The anisotropy correction for ${ }^{252} \mathrm{Cf}$ was not Inown. The fluences were converted to dase equivalent using the methods outlined in NCRP 70.6 The calculated values ase reported. In general two to four detectors were used per irradiation condition. Variations as large as $35 \%$ wera somatimes obuerved between detectors exposed to the same neutron dose equivalent. No differences in sengitivities were observed heiween the three batches of detectors.

The photon exposures were made with a Clinac 1800 medical accelerator. Three detectors mounted on a styrofoam stand were placed on the treatment couch auch that the detectors were insido the primary beam in the patient plare. A Geld size of $35 \mathrm{~cm} \times 35 \mathrm{~cm}$ was used. Two detectors similarjy mounted were placed outside the beam at a distance of $50 \mathrm{~cm}$ from the isocenter in the patient plane.

The CR-39 used in this study was obtained from American Acrylica and Plastics, Inc., U.S.A. The detectors $1.587 \mathrm{~cm} \times 2.85 \mathrm{~cm} \times 0.063 \mathrm{~cm}$ in dimensions were covered with a polyethylene layer of thickness $0.01 \mathrm{~cm}$. All irrediations were performed with the polyethylene Intact. Two etching procedures were used. Procedure A consisted of an electrochemical etch in $6.5 \mathrm{~N}$ KoH at 1500 volts, 60 $\mathrm{Hz}$ and $60^{\circ} \mathrm{C}$ for five houra, followed by a bigh frequency etch at $2 \mathrm{kHz}$ for 23 minutea (blow-up step) and a 15 minute post etch in the oven to smooth the tracks for counting. Prncedure B conststed of a similar etch but at a higher voltage of 3000 valts with time reduced to three hours. 


\section{RESULTS AND DISCUSSION}

More detailed descriptions of factora that affect the regponse of the BD $1 D n$ are reported elsewhere. ${ }^{7}$

\section{BACKGROUND}

The average background on a sensilized unirradiated delector varjed generally from about $\mathbf{0}$ to 3 bubbles. Hence no background subtraction was made in the number of bubbles reported for irradiated detectors.

\section{FORMATION AND GROWTH OF BUIBHISS}

Bubble size distribution and concentration were non uniform within thr detector with the concentration at the top of the delector medium being much greater than elsewhere within the detector. The growth rate was grealest the first day but growth continued for wecks.

\section{EFFECT OF STORAGE TIME}

There was no significant difference between the number of bulbles ublained for delectors exposed to a given neulron dose equivalent whes counterl one day and five months after irradiation. This indicaled that the detector did not un. dergo any significant fading during this time period.

The detector medium of a sensitized unirradiated detector stored at runtn temperature without the cap started deteriorating after two weeks. Adding freon and recapping the detector prevents deterioration during storage. 


\section{EFFECT OF IMPACT}

Irradiated detectors that were accidentally dropped on the floor one day after irradiation produced clusters of tiny bubbles in addition to existing ones as can be seen from Figure 1. The larger bubbles are due to neutron irradiation.

\section{EFFECT OF PHOTON IRRADIATION}

A sensitized detector exposed to $15 \mathrm{~Gy}$ of ${ }^{60} \mathrm{Co}$ gamma rays produced no bubbles. $X$-ray imaging and energy dispersant $X$-ray analysis of a small portion of the detector medium indicaled that it has some high atnmic number constituenta. This makes the detector inherently self shielding at low gamma energies. In addition at theas low energies the gamma rays interact mainly with the electrons and are not very efficient at depositing their encrgy locally. ${ }^{8}$ Thus the nD-100 is insensitive to low entergy gamma rays. At higher energies $(\geq 6 \mathrm{MeV})$ where the photon energy is comparable to the binding energy per nucleon, the probability of photo-nuclear interactions increases.

In order to atudy the effect of higher energy photons the bubble detectors were exposed ingide and outside the primary bremsstrahlung beam produced by $6 \mathrm{MeV}$ electrons. The exposures were made so that the detectors inside the primary beam received a doac of $10 \mathrm{~Gy}$. The average number of bubbles and the shandiard deviation for the three detertors was 06 I 7. These bubbles are probably duc to the protons generated by the ploto-disintegration of the deuterium in the hydrogen which is a constiluent of the detector medium. This reaction has an energy threshold of $2.22 \mathrm{MeV}$. Of the two detectors placed ontside the primary 
beam one detector had flve bubbles, the other had none (when the total dose inside the primary beam was $20 \mathrm{~Gy}$ ).

\section{EFFECT OF TEMPERATURE}

The sensitivity of the detector depends on $\Delta \mathrm{P}$ which in turn is determined by the vapor pressure of the liquid droplets. As the temperature of the detector increases the yapor pressure increases, thus increasing the sensitivity. Temperature corrections for the BD-100 can be made using the tenperature dependence curve provided by the manufacturer. However caution must be exercised in applying any temperature correclion when the detector is irradialud in an environmert. at a higher ambient temperalure than $20^{\circ} \mathrm{C}$. This is because the $B D \cdot t 00$ has an inherent thermal lag, i.e., the detector medium inside the tube takes some time to reach the ambient temperature when moved from an area where the ambient temperature is different. The changing sensitivity with temperature must br taken into account especially for short irradiation times.

The effect of temperature on sensitized unirracliated delectors can bre sinu in Figure 2. The first two delectors were heated in a water bath for alkmit ds minutes at approximate temperatures of $40^{\circ} \mathrm{C}$ and $48^{\circ} \mathrm{C}$ respectively. The thircl detector was lefl on the dashboard inside a closed car for aboul it hours whent

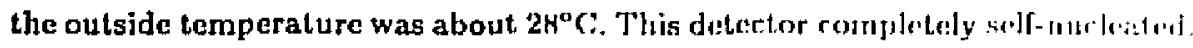

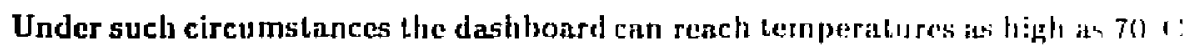

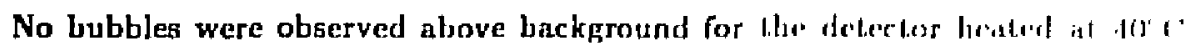
However, as is evident from the photographts, the B1) 100 is therm: Ify unistitule when heated to ternparatures of $48^{\circ} \mathrm{C}$ or greaten. 


\section{LINEARITY OF RESPONSE}

The response of the BD-100 was found to be fairly linear when exposed to PuBe neutrons in the dose equivalent range of 40 to $170 \mu \mathrm{Sv}$. The limitation on linearity is governed to a large extent by the maximum number of bubbles that can be counted effeiently. Counting a large number of bubbles becomes dificult because of overlapping and the fact that the geometry of the detector does not lend jtaelf to good resolution of irdividual bubbles.

\section{ENERGY RESPONSE}

The bubble detoctorg mounted on a water phantom were exposed to noutrons From atanfard aources such as $\mathrm{PuBe}, \mathrm{PuB},{ }^{252} \mathrm{Cr}, \mathrm{PuF}$ and $\mathrm{PuLi}$, with average energies of $4.5,2.3,2.15,0.9$ and $0.5 \mathrm{MeV}$ respectively. Figure 3 shows the sensitivity of the the BD-100 as a function of average neutron energy. The average values are plotted at each energy. The error bars represent the standard deviations of the detectora. The curve is drawn only to aid the eye. The solid dots are the results of irradjations performed at ambient temperatures higher than $20^{\circ} \mathrm{C}\left(i, e ., 35-40^{\circ} \mathrm{C}\right.$ ) and the trlangles are for irradiations performed at an ambient temperature of about $20^{\circ} \mathrm{C}$. The open circles represent the values obtained when the higher ambient temperature results are corrected for $20^{\circ} \mathrm{C}$. The error bars for the open circles include an uncertainty of about $20 \%$ for the temperature corrections. The application of a temperature correction is not atraight forward due to the lact that a) the detector has a thermal lag which depends on the difference between its temperature and the ambient temperature and b) there are variations in the ambient temperature during the period of Irradiation. Some preliminary experiments indicate that it takes at least ten 
minutes for $\mathrm{u}_{1}=$ dntector to reach a controlled ambient temperature of $300^{13}(\mathrm{~S}$. Srum jts temperature of $19^{\circ} \mathrm{C}$. However further refined studjes are necessary. A tharmal lag of 15 minutes was asstumed in making the temperature corrections. Thu: only conclusion that can be drawn (rom thege results is that the response of the (13D) 100 appears to be energy dependent, the sensitivity generally increasing with decreasing neutron energy. The sharp increase in response to ${ }^{252} \mathrm{Cr}$ firatrons is nat fully understood.

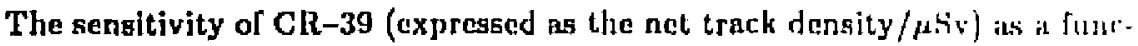
tion of average neutron energy is shown in Figure 6. 'lhe solid dotis represisit. the results using etching procedure $A$ and the open circles represent the rosilis using etching procedure $B$. There does not appear to be any differetro lextwerll the two procedures oxcept at 4.5 MeV. Clearly CR-39 has a more pronounced dose equivalent energy dependence tlan the $\mathrm{BD}-100$.

\section{CONCLUSIONS}

The ED-100 has many properties such as ite high sensitivity, low thashold or detection, and isolropic response which make it a desirable neutron detector. However there are some factors that influence its response, sucl, as trmperiturn and impace which limit its use in the practical aspects of neatron chositreetr: The restriction of "use within eight hours alter sengitisation" and the dillirulty of counting a targe number of bubbing are additional handicips. The J3I tho in also sensitive to high energy photons. In addition the retector tias a respmusr that appears to be energy dependent. Electrochenically etchrd CH 34 has as more pronounced erergy dependence.

If most of the above mentioned problems can be overcome, the 13I) I06 would be a welcome addition to the field of neutron dosimetry. 


\section{RUNORWNCES}

1. Ing, H. The Status of the Bubble-Damage Polymer Detector. Nuel. Tracks Radiat. Meas, 12(1-6) 49-54 (1986).

2. Technical Note. Novel Inerpenvive Neutron Bubble Detector (BD-100). Chalk River Nuclear Laboratories, Chalk River, Ontario, Canada.

3. Apfel, R. E. and Roy, S. C. Superheated Drop Detector: A Possible Alternative for Neutron Dosinetry. Radial. Prot. Dosim. 10(104) 327-330 (1985).

4. Apfel, R. E., Roy, S. C. and Lo, Y. C. Predietion of the Minimum Neutron Energy to Nueleate Vapor Bubbles in Superhealed Liquirts, Plyss. Review A 31 3194-319B (1085).

5. lng, 13. J'rivale conmunication.

f. Neutron Contaninution Jrom Medical Eleetron Acceleratore. NCRP Report No. 79 12-16 (1081).

T. Ipu, N. E. and Busick, D. D. BD-100 - The Chalk River Nuelear Laboraluriea Newtron Hubble Datector, StAC-PUB-4398, Stanford, California; U.S.A. (1987).

B. Aprel, R. B. The Superhealed Drop Detector. Nucl. Instrum. Methoda 102 (60):-601 (11271). 


\section{FIGURU Captions}

Fig. 1. Effect of impact.

Fig. 2. Effect of temperature on gensitized unirradiated detector.

Fig. 3. Senaitivity of BD-100 as a function of average neutron energy.

Fig. 4. Sensitivity of CR-39 as a function of average neutron energy. 



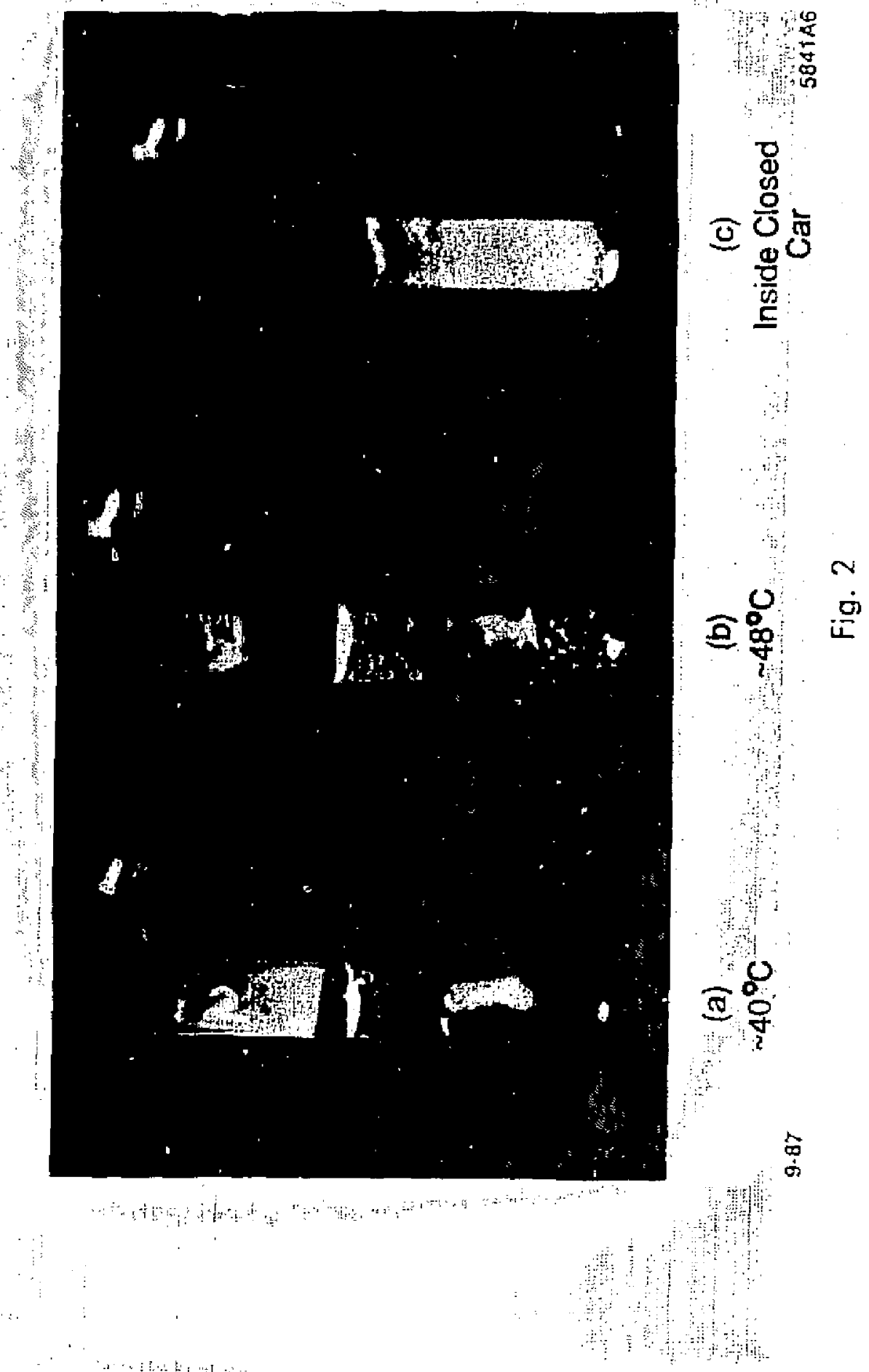




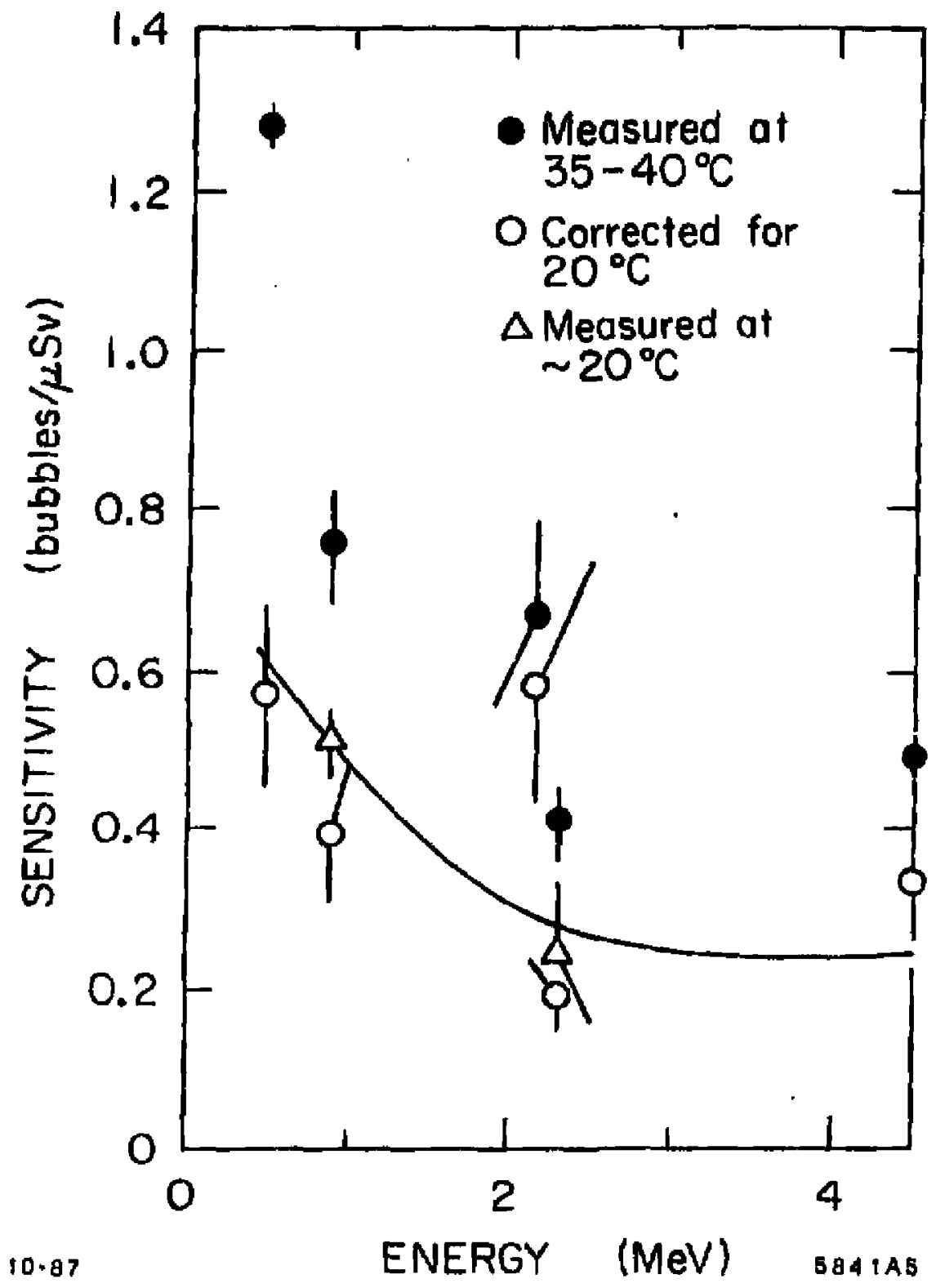

Fig. 3 


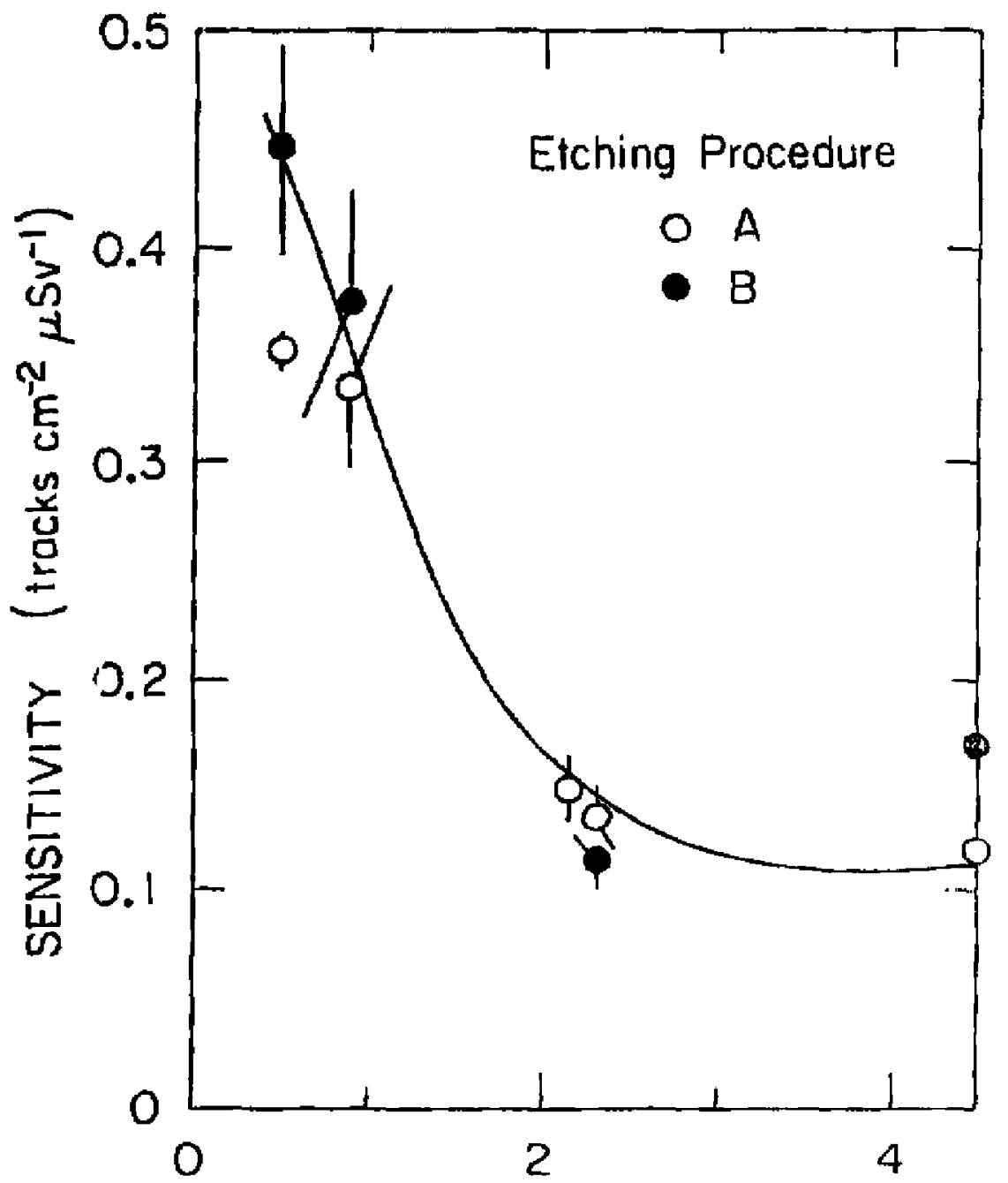

10-87

ENERGY (MeV)

$5641 \mathrm{AA}$

Fig. 4 